\title{
EL ESTUDIO DE LA LITERATURA HISPANOFILIPINA DURANTE EL SIGLO XX
}

\author{
THE STUDY OF SPANISH-FILIPINO LITERATURE \\ DURING THE XX ${ }^{\mathrm{TH}}$ CENTURY
}

\author{
Jorge Mojarro Romero \\ University of Santo Tomas \\ mojarro@gmail.com
}

\begin{abstract}
RESUMEN: El presente estudio ofrece un recorrido cronológico y comentado de las aportaciones críticas más relevantes en el área de la literatura hispanofilipina a lo largo del siglo xx. Dada la relativa parquedad del corpus crítico, se incluirán aportaciones que, aun sin ceñirse al estudio de la literatura filipina en lengua española, ilustran fehacientemente cómo se ha definido esta área de estudio, qué obras han merecido mayor atención, qué criterios se han seguido para seleccionar las obras, cómo se ha periodizado la literatura hispanofilipina y qué metodologías se han seguido. Las conclusiones permitirán establecer un balance bastante aproximado de los avances realizados durante el siglo xx en esta área de estudio.
\end{abstract}

Palabras clave: Literatura hispanofilipina; historia de la literatura; crítica literaria; periodización; siglo Xx.

ABstRaCt: This paper offers a survey of the most relevant critical approaches in the field of Spanish-Filipino Literary Studies with the aim of charting its development up to the year 1999. Given the relatively limited size of the corpus, this paper will treat studies that, although not focused directly on Spanish-Filipino Literature in Spanish, highlight how the field has been defined, which works have deserved more attention, what were the criteria used to select canonical works, what periods have been established, and what dominant methodologies have been employed to date. This will allow us to draw important conclusions about the development of scholarship in this area during the twentieth century.

Keywords: Spanish-Filipino literature; literary history; literary criticism; periodization; $20^{\text {th }}$ century.

Recepción: 8 de febrero de 2017; aceptación: 23 de noviembre de 2017. 
La literatura hispanofilipina* nace, como la hispanoamericana, de la mano de los diarios de navegación, cartas de relación e informes etnográficos escritos por navegantes y misioneros bajo el impulso de la expansión colonial. Los primeros escritos datan aproximadamente de 1521 y son productos testimoniales de la expedición transpacífica emprendida por Magallanes y culminada por Elcano. Desde principios del siglo XVII hasta hace relativamente muy pocas décadas, la literatura filipina en lengua española gozó de una posición central en el seno de las varias literaturas del archipiélago. El año de 1604 es clave, porque es la fecha en que el dominico Francisco Blancas de San José (¿?-1614) funda la primera imprenta de tipos, que dará lugar al desarrollo de una amplia literatura colonial de orientación predominantemente religiosa ${ }^{1}$. La segunda mitad del siglo xıx, gracias a la implosión de élites locales y a la implantación masiva de un sistema educativo a imitación de aquellos que pocos años antes funcionaban en Europa, verá el despegue de un universo literario propio que tendrá sus mejores años durante el período de ocupación americana. Sin embargo, la mayor parte de este inmenso corpus de obras literarias ha quedado condenada al olvido, y su estudio crítico, como se verá, ha carecido de continuidad y sistematicidad, por lo que en las siguientes líneas he creído conveniente trazar un recorrido cronológico de estos aportes a lo largo del siglo xx, con el objetivo de entender el proceso histórico de desaparición de la literatura hispanofilipina y, al mismo tiempo, ofrecer al estudioso una bibliografía comentada a partir de la cual empezar a trabajar en aras de recuperar un rico corpus de textos, tanto del período colonial como del siglo xx, relegado en el ámbito de las literaturas hispánicas. Empleo este criterio porque no se observan dentro de la crítica literaria filipina movimientos ni tendencias notables, sino la aparición de estudios aislados e inconexos en número descendente desde 1898 hasta la década de los años sesenta, en que se percibe un resurgimiento del interés en el estudio de la literatura hispanofilipina que va en aumento hasta la última década del siglo xx y cobra un impulso decisivo en lo que va del siglo $\mathrm{XXI}^{2}$.

* Mi más sincero agradecimiento a la profesora Ángela Martínez Hadad (University of the Philippines-Diliman) por ayudarme a conseguir algunos artículos publicados en revistas académicas filipinas de difícil localización y a los oportunos y útiles comentarios de los revisores anónimos de la Nueva Revista de Filología Hispánica. Téngase en cuenta, durante la lectura, que los apellidos filipinos de origen español ya no se acentúan.

1 Véase Mojarro 2018.

2 Este resurgimiento, que incluye la aparición de estudios monográficos de entidad, números especiales de revistas y la recuperación en ediciones anotadas de algunas obras, requiere un estudio aparte en el que estamos trabajando. 


\section{Desde Retana hasta los años Cincuenta}

Como ocurre con muchos de los temas relacionados con el hispanismo en Filipinas, las primeras aproximaciones críticas a la literatura hispanofilipina se deben al erudito y bibliófilo Wenceslao Retana (1862-1924) ${ }^{3}$. Si exceptuamos los numerosos y sustanciosos datos aportados en su monumental Aparato bibliográfico para la historia general de Filipinas (1906), sus dos primeros estudios rigurosos acerca de la literatura filipina en español vieron la luz en 1909: De la evolución de la literatura castellana en Filipinas y Noticias histórico-bibliográficas de el teatro en Filipinas desde sus origenes hasta 1898. La primera de estas obras es un estudio breve dividido en varios bloques que tiene como propósito denostar el Modernismo que los poetas del archipiélago habían adoptado a principios del siglo xx. Retana (1909, p. 5) concibe la literatura desde presupuestos románticos: "la expresión de lo que siente y piensa el pueblo", y tan sólo se refiere "a lo escrito en castellano por los filipinos de sangre filipina”, excluyendo con este criterio incluso a los escritores criollos. En una obra publicada en 1908, arguye que la condición misérrima de la poesía en lengua española se debe a la histórica injerencia de un clero omnipresente que hizo todo lo posible para que los indígenas no aprendieran el español y aplicó efectivamente una férrea censura.

Retana sólo cuenta dos poetas durante el período español: Pedro Paterno (1857-1911), que publicó Sampaguitas (1880) en Madrid, y José Rizal (1861-1896), cuya poesía, publicada en revistas dispersas, sólo se logró reunir póstumamente. El estudioso madrileño advierte la eclosión de una poesía de tintes patrióticos durante la década de ocupación estadounidense representada por José Palma (18761903), autor del himno nacional filipino, y Cecilio Apóstol (18771938). Sin embargo, tanto de este último como de Fernando María Guerrero (1873-1929), Jesús Balmori (1887-1948), Manuel Bernabé (1890-1960), Vicente Peláez y Pacífico Victoriano reprueba su viraje hacia el Modernismo, traído por "esos calamitosos hispanoamericanos degenerados en París que, exentos de corazón, componen con el cerebro" (1909, p. 9). Retana procede a través de la presentación de poemas completos y el examen textual subsiguiente. Incapaz de apreciar los valores de la nueva poesía, lamenta que "lo que triunfa es lo indeciso, lo fantástico, lo falsamente tristón, lo bohemio... Lo que triunfa es la deslocalización de la poesía filipina” (p. 35). Detrás de su crítica no hay sólo incomprensión, sino la desilusión ante un programa de poesía que se alejaba de la realidad, evitaba el tratamiento

${ }^{3}$ Los trabajos de este incansable y polémico investigador aún no se han valorado en su justa medida. Algunos artículos que han tratado de estudiar su figura son los de John N. Schumacher 2008 y Glòria Cano 2008 y 2008 a. 
de los problemas nacionales y prefería hablar de lirios y crisantemos a enfrentarse con la dominación norteamericana. Retana, en fin, temía que la falta de compromiso de la poesía acabaría contribuyendo a la deshispanización del archipiélago. No entendió que los autores filipinos preferían no realizar reivindicaciones políticas por medio del género lírico, sino mediante artículos de opinión y protesta en la prensa. Desde el punto de vista formal, el folleto es un documento histórico que tiende al sermón o a la arenga. La abundante ilustración de poemas, cuya procedencia no se cita nunca, es lo más valioso y aprovechable de este pequeño ensayo, dada la dificultad para hallar revistas literarias de la época.

La segunda obra es un estudio de mayor envergadura e interés. Escrita con un peculiar estilo narrativo y salpicado de curiosas e informativas digresiones, El teatro en Filipinas hace un recorrido muy documentado del género desde su aparición a finales del siglo XVI hasta la pérdida de la colonia en 1898, que se ha convertido en referencia para todos los estudios del teatro en Filipinas ${ }^{4}$. Retana demuestra que los filipinos desconocían el género teatral antes de 1572 y que su introducción vino de mano de los padres jesuitas, pioneros en la difusión de la cultura literaria y musical en el archipiélago ${ }^{5}$. Reconstruyendo diligentemente a partir de datos esparcidos en diferentes crónicas y cartas misioneras, Retana concluye que las primeras representaciones, de carácter netamente religioso, tuvieron lugar en Cebú, por iniciativa del jesuita Pedro Aguarto, en 1598, y en la isla de Bohol, en 1609. Añade que en Manila la primera representación, y de una obra de título conocido: Comedia de la hermosura de Rachel ${ }^{6}$, se hizo durante las fiestas de la Inmaculada Concepción en 16197.

Retana añade información de gran valor: en primer lugar, el nacimiento del teatro de moros y cristianos con motivo de la toma de

${ }^{4}$ La obra tiene un precedente de poco valor -Rizal la critica con saña y Retana la ignora deliberadamente- en Vicente BARRANTEs 1889.

${ }^{5}$ Los chinos de Manila, lógicamente, conocían el teatro y hacían representaciones en sus festividades, aunque en éstas no participaban los filipinos. Así, la primera crónica dominica aduce: "En lo que más cuidado puso «el padre Cristóbal de Salvatierra», y más dificultad halló, fue en prohibir a los chinos infieles las comedias que hacían, y a los españoles y españolas el salir a verlas, de la manera que las hacían, que era llena de supersticiones y idolatrías" (DiEgo De AduARTE 1962, t. 1, p. 306).

${ }^{6} \mathrm{Su}$ autor es Luis Vélez de Guevara (1579-1644) y se imprimió en Madrid en 1615. Cf. Héctor Urzáiz 2002, t. 2, p. 702. Es bastante probable que las primeras obras se representaran en Manila con anterioridad a esa fecha, pero desafortunadamente no disponemos de ningún documento que lo atestigüe.

${ }^{7}$ Retana (1909) apunta en p. 28 que las fiestas se hicieron en 1619 "con ocasión de la llegada a Manila de una bula de Urbano VIII". Esto es del todo improbable, ya que su papado apenas comenzó en 1623. Debe referirse a un decreto en favor de la Inmaculada Concepción de Paulo V, que se imprimió en 1617. La datación de las celebraciones debe ser cierta, ya que el raro impreso en que las describe fue publicado en Sevilla en 1621. 
Iligan, pueblo de musulmanes, en Mindanao (1637). Este género teatral, de carácter no religioso y que virará rápidamente hacia lo amoroso -historias truculentas sobre moros y cristianos que eventualmente se enamoran-, será extremadamente popular durante los dos siglos siguientes, si bien con una llamativa peculiaridad:

Se da el extraño caso de que el moro de la literatura filipina sea siempre, invariablemente, el moro arrogante, seductor y de larga y espesas barbas de la literatura importada, el moro de la literatura española; es decir, el moro desconocido, jamás el moro que durante siglos enteros asoló cuanto pudo las costas de Bisayas y Luzón (Retana 1909, pp. 34-35) ${ }^{8}$.

En segundo lugar, Retana da noticia de las primeras obras teatrales impresas en Filipinas en Sagrada fiesta tres vezes grande: que en el decurso de tres días zelebró el convento de Santo Domingo en Manila... ${ }^{9}$. Sin embargo, no pudo conocer un importante manuscrito: Relación verdadera de las exequias funerales que la ynsigne ciudad de Manila celebró a la muerte de la magestad del Rey Felipe Tercero y reales fiestas que se hiçieron a la feliçe suçesión de su único heredero y señor nuestro Felipe 4 (Manila, 1623), de Diego de Rueda y Mendoza, obra que no se llevó a la imprenta por motivos desconocidos y que antecede en más de cincuenta años a la edición príncipe del teatro en Filipinas ${ }^{10}$.

En tercer lugar, Retana documenta exhaustivamente el nacimiento del teatro moderno durante el siglo xix y analiza todas las obras de cuya existencia ha podido obtener información: así, localiza teatros, apunta la creación de asociaciones culturales, enumera a los actores participantes, recaba información acerca de todos los autores y da cuenta de todas las obras teatrales impresas o representadas, pintando, en definitiva, un fresco de la vida cultural manileña a finales del siglo $\mathrm{XIX}^{11}$.

8 Acerca de este peculiar subgénero, véase IsAaC Donoso 2010, t. 11, pp. 87-120.

${ }^{9}$ El título completo es Sagrada fiesta tres vezes grande: que en el decurso de tres días zelebró el Convento de Santo Domingo en Manila, primera casa de la Provincia del Sancto Rosario de Filippinas: en la beatificación de los gloriossos sanctos Pío Quinto, Diego de Bebaña y Margarita de Castello. Hay ejemplares en la National Library of the Philippines y en las bibliotecas de la Universidad de Hamburgo y Fray Francisco de Burgoa (Oaxaca). Se trata de un volumen en papel de arroz que incluye, además de loas, poesías, sermones, un entremés y un sarao, tres comedias escritas por un fraile dominico, probablemente vasco. Los títulos de estas "comedias nuevas" son: El gobierno del sancto Pío Quinto, Los albores de la rosa y Las virtudes de la rosa, todas "en tres jornadas". Todo el volumen es de sumo interés, ya que testimonia la íntima relación entre cultura literaria, festividad y religión en el origen de la dramaturgia colonial durante el siglo xvir. Cf. Miguel Zugasti 2016.

${ }^{10}$ Cf. Miguel Martínez 2016 y 2017. El profesor Martínez está trabajando en la edición del manuscrito.

${ }^{11}$ Cf. C. Lacónico-Buenaventura 1979 y 1998. Comento ambos trabajos más adelante. Por otra parte, Leoncio CAbrero Fernández 1973-74 viene a ser síntesis y paráfrasis del trabajo de Retana. 
Cierto es que El teatro en Filipinas podría ser reescrito en la actualidad con criterios filológicos más modernos, atendiendo a una concepción más abierta de la obra literaria y, quizás, con un estilo menos personal, pero no cabe duda de que gracias a su erudición útil, su sagacidad investigadora y su exhaustividad informativa, es una obra de referencia para conocer tanto el desarrollo del género dramático desde su implantación, como el funcionamiento y la transformación del sistema literario, especialmente interesante en lo que se refiere al último tercio del siglo decimonono.

Tras el prometedor y valioso impulso de Retana vendrían largas décadas de abandono crítico e incluso de rechazo explícito. Aunque el período de ocupación estadounidense (1898-1946) fue el más prolífico para la creación literaria filhispana, esta riqueza no vino acompañada de un quehacer crítico que sistematizara las obras que se iban publicando, a excepción de las consabidas reseñas que salían puntualmente en revistas y periódicos. Así, un apresurado artículo del polígrafo filipino Cristóbal Epifanio de los Santos (1871-1928), publicado en 1914, distingue tan sólo dos literaturas escritas por filipinos: la tagala y la castellana, y remonta el inicio de la literatura en espanol a las poesías de Fernando Bagongbanta contenidas en el libro Memoriales $(1606)^{12}$ y a la pionera gramática de español para tagalos de Tomás Pinpin $(1610)^{13}$. Tras ensalzar las virtudes innatas del filipino para el estudio, la poesía y la música, pasa a enumerar poemas, autores y fechas para el fecundo período 1895-1900. Sin referencias ni ejemplos, ni mención de alguna revista, poco de aprovechable hay en la bienintencionada contribución de Epifanio de los Santos.

En 1935 apareció una tesis de licenciatura titulada La literatura castellana en Filipinas, más interesante como documento histórico que como investigación, en que la autora escribe motivada por el deseo de registrar una literatura ya en declive:

El más curioso fenómeno que hemos sorprendido durante el curso de estas investigaciones ha sido la rápida decadencia de la literatura castellana en Filipinas después de los cortos pero gloriosos días del más exuberante de los florecimientos ${ }^{14}$.

12 Probablemente se estuviera refiriendo a la obra de Francisco Blancas de San José, Memorial de la vida cristiana, Juan de Vera, Binondo, 1606, escrita en tagalo a pesar del título.

${ }^{13}$ Tomás Pinpin, Librong Pagaaralan nang manga Tagalog nang uicang Castilla, Diego Talaghay, Bataan, recientemente reeditada, sin criterio filológico alguno, por D. Woods (UST Press, Manila, 2012).

14 Delfina de San Agustín 1935, p. 2. La estudiosa constata un hecho que ya anunciaban algunos autores mucho antes, entre ellos Teodoro M. Kalaw: "Yo soy de los primeros en augurar un porvenir sombrío a la literatura castellana en Filipinas. Hace unos cinco años lo predije y hoy sostengo lo dicho. No ciertamente por creer en la impotencia de nuestros elementos contra la pretendida imposición de elementos 
El trabajo está dividido en tres partes: la primera trata de "la edad de oro de la literatura castellana en Filipinas", en la que se incluye a Rizal, Paterno, Guerrero, Apóstol y José Palma; la segunda analiza a algunos autores más recientes y revistas y pasa, sin transición, a examinar una supuesta decadencia de la lengua española en la prensa escrita debida, en opinión de la autora, al abuso de anglicismos; en la tercera, a modo de reseña apresurada, la autora ofrece algunas noticias acerca del Premio Zóbel ${ }^{15}$. Como apéndice, incluye una interesante recopilación de textos titulada "El porvenir de la literatura castellana en Filipinas", en que procede extractando una gran cantidad de poemas, comentados desde un punto de vista psicológico e impresionista. Califica luego a Guerrero y a Apóstol, sin más aclaración, como poetas románticos, mientras que incluye como textos literarios los escritos políticos de Pedro Paterno (1857-1911) y Apolinario Mabini (1864-1903), teórico de la independencia filipina. Asimismo, antologa prosas de Claro M. Recto, Antonio Abad (La redimida), Enrique Laygo (Caretas), Alejo Pica Valdés, Isidro Marfori, José Hernández Gavira, José Teotico, Tirso de Irureta Goyena y Antonio Zacarías, aunque, como suele ocurrir en la temprana crítica literaria filipina, no menciona la procedencia de los textos ${ }^{16}$.

La siguiente contribución al estudio de la literatura filipina en espanol durante el período de ocupación norteamericana es especialmente

extraños, sino por obra decidida y franca del mismo pueblo filipino. Las nuevas generaciones, animadas de un cálculo más o menos justo de sus ambiciones y porvenir, creen más adecuado y racional asistir a las Escuelas de inglés, y servirse de este idioma para ostentar, en la sociedad, las legítimas conquistas de sus estudios y talento. Este es un hecho difícil de refutarse con argumentos teóricos, y a no ser que el pueblo siga la misma actitud de los elementos radicales de la sometida Polonia, hay razón para creer que continuaremos así hasta que cambien totalmente las circunstancias" (apud Claro M. Recto 1911, p. 227).

15 El Premio Zóbel fue un galardón literario que se otorgó entre 1922 y 1999 (no se entregó durante los períodos 1942-1952 y 1967-1973) a las mejores obras literarias filipinas escritas en español. Fue promovido por el magnate y filántropo Enrique Zóbel de Ayala (1877-1943). El itinerario de ganadores y concursantes de este premio es el mejor testimonio de la progresiva decadencia de la literatura hispanofilipina desde su período de mayor esplendor. Sin embargo, desgraciadamente no se encuentra ejemplar alguno de muchas de las obras premiadas que no se llegaron a imprimir. Véase una animada historia del premio en LOURDES BRILLANTES 2000.

${ }^{16}$ Lo más útil de este trabajo es la mención de un gran número de revistas literarias y culturales en español, muchas de ellas ilocalizables hoy, que dan cuenta del dinámico protagonismo, aunque decreciente, de la lengua española en la vida cultural del archipiélago durante los años de la ocupación estadounidense: El Renacimiento Filipino, fundada por Martín Ocampo, de 1901 a 1903; Domus Aurea, editada por Sixto Roces, salió en 1908 y se interrumpió después del cuarto número; Cultura Filipina, editada por Narciso Rangel, de 1910 a 1915; La Minerva, dirigida por Esperanza Poblete, salió años más tarde; La Alborada, dirigida por Rafael Corpus y Pacífico Victoriano; y Excelsior, de1903 a 1934, por lo menos. De entre los periódicos, cita tan sólo tres: $E l$ Renacimiento, República Filipina y Feria de Novedades. 
relevante, porque su perspectiva reaccionaria y sus análisis influirán decisivamente en la confección de manuales escolares hasta el día de hoy. De hecho, A brief history of Philippine literature (1937), de Teófilo del Castillo y Tuazon, se reeditará en numerosas ocasiones hasta principios de los años ochenta, pues se constituyó en referente de la enseñanza de la literatura en las escuelas públicas ${ }^{17}$. El plan del libro es decididamente irregular; ante la problemática de la diversidad de lenguas y géneros en la literatura filipina, Castillo organiza la obra en secciones más bien arbitrarias: los tres primeros capítulos (literatura prehispánica, canciones populares filipinas y poesía vernacular) atienden a una distinción que propiamente no existe; todo podría haberse agrupado bajo un mismo marbete. Asimismo, el autor conjetura sobre la base de cierto alfabeto que demostraría la existencia de una cultura literaria en papel, supuestamente destruida por los frailes ${ }^{18}$, y extracta poemas épicos, canciones populares y poemas, en una distinción genérica poco clara. El siguiente capítulo, dedicado al drama, es en su mayor parte una rápida síntesis del trabajo de Retana que he comentado anteriormente. Los capítulos quinto (poesía filipina en español) y sexto (prosa filipina) son los de mayor interés para el hispanista: el primero de ellos contiene una gran cantidad de autores e intercala una gran selección de poemas y fragmentos; el otro está formado por una lista no muy larga de novelas, en su mayoría, escritas en español ${ }^{19}$.

Castillo es consciente del carácter pionero de su trabajo: tratándose de la primera historia literaria filipina, la introducción consiste en un alegato en favor de la importancia de la literatura en el fomento del orgullo nacional, con especial énfasis en la población del archipiélago filipino y la cultura literaria anterior a la llegada de los españoles. El nacionalismo de Castillo está fuertemente imbuido por la propaganda contemporánea estadounidense y acaba por caer, en numerosas ocasiones, en una hispanofobia, resultado de la idealización, por desconocimiento, de la Filipinas prehispánica:

The written literature of the Filipinos is only about four hundred years old, a very short period when compared to that of many other countries, or when compared to the length of time our ancestors have lived in these Islands. Various causes are responsible for the brevity of its history; but the chief contributing factor to this unfortunate condition was the

${ }^{17}$ Aunque con título diferente (Philippine literature from ancient times to the present), su contenido es el mismo, a excepción de las actualizaciones acerca de las obras publicadas en los últimos años.

${ }_{18}$ No hubo tal destrucción: antes de la llegada de Legazpi no existía una cultura de la letra impresa. El alfabeto filipino se usaba para otros menesteres. Cf. WALter HenRY SCOTT 1984, pp. 53-58.

19 Apenas menciona alguna que otra novela en inglés -la primera de ellas, la mediocre A child of sorrow, de Zoilo Galang, es de 1921-y algunas obras en lenguas filipinas. 
destruction of our written native literature in the early days of Spanish dominance $(1937, \text { p. } 7)^{20}$.

En consecuencia, la historia de la literatura filipina viene a ser una historia de la cercenación creativa de los filipinos por parte de los españoles, que sólo recientemente empieza a resurgir de mano del inglés, lengua de la libertad:

It was inevitable that the conquest should very definitely limit the further growth of vernacular literature, not only because of repression of those practices from which spring the inspiration of literary effort, but also because the people themselves, having been conquered, preferred the culture of Spain to their own. Since the Spaniard had proved his superior martial ability, the Filipino came to think that the same superiority carried over into other departments of life. This blind imitation and false evaluation were encouraged by the Spaniards. So true literature of the people was neglected while our poets and singers satisfied themselves with puerile attempts to copy Spanish themes and Spanish forms (p. 123).

\section{Castillo divide la literatura filipina en cinco períodos:}

Desde los inicios hasta 1565: etapa caracterizada por la creación de poemas épicos, adivinanzas, proverbios, leyendas y poemas líricos. Para Castillo es la época dorada de la literatura filipina, en razón de que ésta surgía directamente del espíritu del pueblo.

De 1565 a 1820: período de imitación y decadencia literarias por causa de la subyugación y la opresión. El pueblo filipino pierde frescura y virilidad, por lo que, en consecuencia, se da un estancamiento creativo y las obras se vuelven imitativas, vacías e insignificantes. Afirma categóricamente que la imprenta llegó en 1610 sólo para publicar obras religiosas, cuando lo cierto $-\mathrm{y}$ ya sabido por entonces- es que los primeros libros se estamparon en 1593 y se permitió la impresión de obras no religiosas, aunque constituyeran minoría. Todo esfuerzo creativo era deliberadamente obstruido y suprimido. También asevera, sin ofrecer pruebas, que la única literatura española que llegó a Filipinas fueron los poemas épicos ${ }^{21}$.

Desde 1820 a 1895: período de renacimiento. La llegada de formas más liberales de gobierno, la difusión de periódicos, la apertura del canal de Suez en 1869, el florecimiento de una clase burguesa, la implantación de la educación pública y la llegada de libros extranjeros contribuyen al desarrollo de la literatura.

${ }^{20}$ Huelga decir que Castillo no prueba documentadamente el aserto.

${ }^{21}$ Es difícil comprender estas últimas afirmaciones, dado que el autor parece conocer las investigaciones bibliográficas de Retana. La imprenta de tipos móviles llegó a Filipinas en 1604. Véase la referencia de la nota 1. 
De 1895 a 1908: período de transición que, en medio de la censura, ve alzarse una literatura patriótica y subversiva.

Hasta 1937: período contemporáneo, que atestigua el resurgimiento de la novela y la aparición de nuevos talentos en inglés.

A pesar de sus graves defectos, la obra de Castillo constituye un primer y notable esfuerzo por realizar una sistematización de toda la literatura filipina. Considerando siempre la literatura como obras de imaginación -no dedica ningún apartado al ensayo-, y sin distinguir propiamente entre literatura oral/popular y literatura escrita/culta, Castillo constriñe su trabajo a autores nacidos en el archipiélago en cualquier lengua y yerra al tratar de explicar los condicionantes culturales que incidieron en el desarrollo y las peculiaridades de la literatura filipina. Muy estrecho de miras, lleno de imprecisiones y prejuicios, escribe impulsado por el deseo explícito de establecer una literatura nacional genuinamente filipina, de ahí que no guarde especial aprecio por los interesantes awits y corridos, formas filipinas de expresión literaria en lengua vernácula de carácter hispano que trataban temas extranjeros (preferentemente leyendas europeas), ni por las pasiones, poemas de tema religioso en tagalo, extraordinarios y originales ejemplos de hibridez cultural. De mucho valor es, empero, la bibliografía final, que recoge gran cantidad de obras de autores hispanofilipinos difíciles de localizar, especialmente aquellas de principios del siglo xx, y supone una buena base para empezar a realizar un corpus ${ }^{22}$.

Esta primera fase de los precarios estudios literarios hispanofilipinos debe concluirse con la modesta aportación de Jaime C. De Veyra, quien en un breve artículo de 1958 reúne asistemáticamente datos que había ido recopilando de estudios anteriores, pero también incurre en ciertos errores e imprecisiones ${ }^{23}$. Citado frecuentemente por haber aparecido en una ambiciosa obra divulgativa, lo más valioso de

${ }^{22}$ Una primera continuación de esa visión restringida y romántica de nación literaria se encuentra en el trabajo de Panganiban y Panganiban (s.f.), en cuya página 4 se afirma que "the literature of the Filipino would be the verbal expression of their affection as acted upon by their relation with the fact of daily life, social practices and religious beliefs". Aunque considera patrimonio filipino cualquiera de sus literaturas, independientemente de la lengua en que esté escrita, tiene por imitativos y decadentes los géneros transculturales que son originales de Filipinas: awit, corrido, moro-moro, comedya, pasyón o zarzuelas (estas últimas en español). En lo que estrictamente se refiere a la literatura filipina en español, no aporta nada nuevo. Por lo demás, hemos consultado la tesis mecanografiada de Preyssler 1955. Se trata propiamente de una amplia antología de la poesía filipina en español agrupada en seis temas: la religión, la mujer, el amor, la patria y los héroes, el dolor y la naturaleza. Los poetas incluidos son Paterno, Rizal, José Palma, Cecilio Apóstol, F.M. Guerrero, J. Balmori, C. Recto y Manuel Bernabé.

${ }^{23}$ Por ejemplo, afirma que Barlaam y Josafat pertenece al mester de clerecía, cuando se trata de la primera novela -aunque traducida- que publicó en el archipiélago el dominico Baltasar de Santa Cruz en 1692, cuya existencia Veyra parece desconocer, ya 
esta contribución son, quizás, la lista de ganadores del Premio Zóbel entre 1922 y 1940 y sus reflexiones acerca del decaimiento de la lengua española.

\section{Desde los años SeSEnta hasta los años OCHenta Del Siglo XX}

La primera historia de la literatura hispanofilipina, a cargo de Estanislao B. Alinea, no vio la luz hasta 1964 y surgió como respuesta a la necesidad de un manual de referencia para las escuelas públicas (según se refiere en p. v). Alinea entiende la literatura hispanofilipina como "el conjunto de obras literarias escritas y publicadas en Filipinas en lenguaje español por los escritores y literatos filipinos (y aún por los españoles que se consideran filipinos a sí mismos)" (p. xiii). Además de observar la literatura como conjunto de fuentes para la historia de la patria y de las ideas, la define como el arte de crear belleza a través del lenguaje; sin embargo, paradójicamente, su método de evaluación no es estético ni literario -aunque atiende a distinciones genéricas-, sino que procede, con obras y autores, según un criterio fuertemente moral.

Alinea plantea una original y estricta periodización de la literatura hispanofilipina en siete bloques con la que estructura toda la obra:

Período de aprendizaje y preparación: llega hasta 1812 e incluye, como Castillo, a dos autores filipinos (Fernando Bagongbanta y Tomás Pinpin) y a dos españoles: Francisco Blanca de San José, impulsor de la imprenta en el archipiélago, y Francisco Moreno, presbítero y autor de una crónica en 1650 que sólo fue publicada en $1877^{24}$.

Período de desarrollo, de 1812 a 1873: se caracteriza por el nacimiento de una conciencia nacional. Alinea incluye a Luis Rodríguez Varela $^{25}$, a Pedro Peláez (1812-1863) ${ }^{26}$ y a Gomburza ${ }^{27}$, incorporados

que tan sólo se refiere a la traducción tagala de Antonio de Borja en 1712. Cf. JaIme C. DE VeYra 1958, t. 5, pp. 509-525.

${ }^{24}$ Alinea incluye tan sólo a estos dos autores e ignora el resto de la rica producción escrita por misioneros.

${ }^{25}$ Rodríguez Varela (1768-1824) firmaba bajo el sobrenombre de El Conde Filipino. Fue el primer criollo filipino que publicó literatura en español: El Parnaso filipino (1812), cuyo único ejemplar, no catalogado, se encuentra en la biblioteca de la Hispanic Society of America. Un comentario a este libro pionero, con largos fragmentos de poemas, puede encontrarse en Wenceslao E. RETANa 1894. Hacia 1823, Rodríguez Varela fue enviado a la metrópoli acusado de ser un conspirador. Véase la tesis inédita de Ruth de Llobet (2015), además de Retana 1924 y Llobet 2009.

${ }^{26} \mathrm{Su}$ corta obra escrita la constituyen unos folletos en los que protestaba por la discriminación a la que eran sometidos los curas nativos y un discurso apologético de circunstancias. Una documentada biografía intelectual de este minusvalorado y decisivo personaje puede verse en RoberTo Blanco ANDRÉs 2011.

27 Acrónimo popular con que se conoce a Mariano Gómez (1799-1872), José Burgos (1837-1872) y Jacinto Zamora (1835-1872), curas seglares ajusticiados tras la algarada de Cavite (1872). 
según criterios nacionalistas, ya que la obra escrita de todos ellos a duras penas puede ser considerada literaria.

Período de laborantismo, de 1873 a 1896: los autores filipinos trabajan desde España, sobre todo en el periódico La Solidaridad (1889-1895), para exigir reformas administrativas y mejoras en el archipiélago filipino. Según Alinea, los autores más destacados de este período son José Rizal y Marcelo H. del Pilar.

Período de revolución, el cual comprende dos acontecimientos luctuosos: la muerte del héroe nacional, José Rizal, el 30 de diciembre de 1896, y la muerte de Apolinario Mabini, el 13 de mayo de 1903. El fervor nacionalista es, de acuerdo con el autor, el común denominador de todas las obras escritas durante este corto lapso de tiempo.

Período de oro, de 1903 a 1942: conforma el capítulo más extenso y provechoso del libro y el más abundante en datos. Organizado en subcapítulos según el género literario, ilustra de manera elocuente una paradoja: que el momento en que la vida cultural y la producción literaria en español fueron más copiosas tuvo lugar durante la ocupación estadounidense.

Período de decadencia: comienza durante la ocupación japonesa y llega hasta 1945. Alinea no menciona obras ni autores, sino que se limita a comprobar en tres páginas la decadencia del idioma español.

Período de resurgimiento: desde 1945, en que Alinea, autor él mismo de poemas y narraciones, se incluye. Los elementos que ofrece como indicios de ese renacimiento demuestran, con la perspectiva de hoy, que tal reivindicación nunca existió, a pesar del esfuerzo de muchos de sus autores. El abandono del español por parte de la población condenó a la literatura filipina escrita en ese idioma a un estado agónico que dio sus últimos estertores durante los años ochenta ${ }^{28}$.

La historia literaria que Alinea nos presenta es una narración tan estructurada cuanto arbitraria, en la que prevalecen sus gustos personales, criterios morales y apego a la biografía ${ }^{29}$. Escrito con escaso criterio y plagado de digresiones inadecuadas ${ }^{30}$, este modesto trabajo supone sin embargo un gran avance, puesto que propone, por

28 Mucho menos optimista respecto a este supuesto renacimiento se muestra el mismo Alinea (1967, p. 517) en un artículo publicado tan sólo tres años después, el cual constituye una síntesis apretada de su libro de 1964.

${ }^{29}$ Alinea, 1967, pp. 52-57, no distingue entre el autor y la obra; así, el juicio crítico en torno a Apolinario Mabini queda dividido en seis dimensiones: como hijo, como estudiante, como hombre, como revolucionario, como escritor y como político y estadista.

${ }^{30}$ Para muestra, un botón: comentando la moralidad de Solo entre las sombras (1917), de Claro M. Recto, AlineA afirma: "si existe «algo inmoral» en el drama, la alquimia literaria de Recto lo ha transformado en un filón de oro purísimo, tal como Shakespeare lo hizo a sus tragedias Hamlet y Macbeth. Léase el monólogo de Andrés al encontrarse solo ante el cadáver de Gabriela después de haberse marchado Marina. Es una escena que bordea lo sublime" (p. 103). 
primera vez, una delimitación diferenciada para el área de la literatura hispanofilipina, la reivindica como patrimonio del país y trata de destacar su valor en el conjunto de literaturas del archipiélago. Por la enorme cantidad de noticias curiosas que recoge, el amplio muestrario de textos y la extensa inclusión de obras, autores y revistas, la obra de Alinea es una primera referencia ineludible para todo aquel que quiera iniciarse en el estudio de la literatura filipina escrita en español.

Por lo demás, en 1967 vio la luz la que hasta hoy es, a pesar del tiempo transcurrido, la mejor colección de ensayos sobre el sistema cultural filipino y sus diferentes literaturas: Brown heritage: Essays on Philippine cultural tradition and literature, volumen colectivo dividido en cuatro bloques de estudio: tradiciones culturales, literaturas en lenguas vernáculas, literatura en español y literatura en inglés ${ }^{31}$. De entre todas las contribuciones me interesan especialmente cuatro: la primera de ellas está firmada por el historiador bicolano Domingo Abella (pp. 34-48), quien, recogiendo el testimonio hipernacionalista de Castillo, denuesta todo el período colonial español en cuanto que lo iguala a tres siglos de opresión cultural. Abella se burla del trabajo de Alinea y lo califica de "hispanista", término peyorativo que devendrá común para definir en Filipinas a toda persona sospechosa de tener opiniones hispanocéntricas o de albergar simpatías para con el antiguo poder colonial. Afirma que considerar las cartas de Legazpi como literatura es ridículo y, atendiendo a un criterio estrictamente racial -mientras que acusa a los españoles de racistas y niega la existencia del mestizaje-, alega que Rodríguez Varela no puede considerarse el primer escritor filipino, ya que "por sus venas no corría sangre malaya", a pesar de que éste había nacido y vivido en Filipinas la mayor parte de su vida.

La visión ideal y esencialista de Abella sobre la literatura como expresión de un pueblo ataca cualquier producción literaria en español toda vez que, en su opinión, la identidad filipina sólo puede encontrar su verdadero acomodo mediante las lenguas vernáculas: tagalo, ilocano, pampango, cebuano, etc. Recogiendo una idea diseminada por Rizal y Pardo de Tavera, Abella acusa a los españoles de haber mantenido al pueblo filipino en la ignorancia hasta 1863, fecha en que la instrucción pública se instala por decreto en Filipinas; esta ignorancia, alega, sería la causa de que no se hubiera desarrollado plenamente una literatura en español escrita por indios ${ }^{32}$. El

${ }^{31}$ Aunque no voy a dedicar espacio a los ensayos que no tratan acerca de la literatura en lengua española, debe indicarse que el volumen incluye algunos estudios cuya lectura es muy recomendable para conocer la posición de la literatura hispanofilipina en los sistemas cultural y literario del archipiélago.

${ }^{32}$ Abella usa la palabra "indio" en su acepción peyorativa inglesa. El autor ignora que la Universidad de San Ignacio fue fundada en 1590 por los jesuitas, que la Uni- 
historiador bicolano, siguiendo una tradición historiográfica hispanófoba, se apresura a enjuiciar antes de comprender y respaldar con pruebas sus afirmaciones. En cualquier caso, su ensayo es bastante significativo en el sentido de que, además de intentar ofrecer cierta luz sobre la literatura en el archipiélago hasta 1898, separa y entierra toda la producción escrita durante tres siglos, en razón de haber sido elaborada por y para españoles, y contribuye a la incomprensión y al desinterés académico por el estudio de todo objeto cultural previo a la segunda mitad del siglo XIx, fecha en que se produce, en opinión de Abella, el despertar de la nación.

El segundo trabajo en este volumen colectivo que merece nuestra atención es el firmado por el compilador, A. Manuud (pp. 457-482), quien comienza denunciando, en explícita referencia a Abella, el historicismo nacionalista que ha permeado perniciosamente los estudios literarios en Filipinas ${ }^{33}$. La consecuencia de esta desviación, constata Manuud, es que los poemas son valorados atendiendo al sentimiento nacionalista que inspiran y no a su mérito literario, algo cierto si se presta atención a los trabajos críticos que hemos examinado anteriormente. En opinión de este estudioso, la invasión de los historiadores filipinos en el terreno literario, convertido en tierra de nadie, explica que se haya ignorado toda poesía filipina que excluía los temas de la patria y la revolución. Manuud expone y reivindica una visión de la literatura más amplia e inclusiva; aboga por el estudio de toda la literatura producida en el país durante el período colonial, sea de misioneros, criollos o españoles afincados. Esta propuesta, revolucionaria y aperturista, desgraciadamente ha tenido escasa repercusión ${ }^{34}$. Manuud es, además, el primer crítico en tomar conciencia del paupérrimo estado de los estudios de literatura filipina en español ${ }^{35}$, de ahí que proponga como remedio una crítica exegética centrada en el texto, la cual permitiría verdaderamente comprenderlo y propiciar una valoración adecuada basada en sus méritos literarios y estéti-

versidad de Santo Tomás fue creada en 1611 por los dominicos y que otras primeras instituciones educativas creadas siguiendo el modelo europeo entonces vigente, las cuales no excluían a los nativos, fueron fundadas por los jesuitas a finales del siglo XVI. Véanse al respecto los poco citados artículos de Henry Frederick Fox 1965 y 1954. También véase Jose S. Arcilla 1972, así como la clásica obra de Evergisto BAZACO 1953.

33 Un ejemplo extremo de esta tendencia es el libro de Marcelo G. Decena 1965, en el cual se analizan, en una magra antología de textos, escritos varios, informes legales e incluso la primera constitución.

34 Antes de la década de los años noventa, la única excepción entre los críticos filipinos era Florentino Hornedo.

35 "Criticism of works in Spanish is so admittedly incipient that any contribution will probably push rather than retard the effort” (MANuUd 1967, p. 460). Lo mismo se puede afirmar aún hoy. 
$\cos ^{36}$, método que no ha tenido éxito en el país debido precisamente al mencionado declive del español en Filipinas. El breve artículo de Manuud es extremadamente relevante por la ruptura que supone con la instrumentalización histórica a la que había sido sometida la literatura en el país -evidente sobre todo en la lectura puramente nacionalista que se había hecho, y sigue haciéndose, de las novelas de José Rizal- y por el gran avance en la concepción teórica y la praxis dentro de la adormecida crítica literaria del país, incapaz de aproximarse a los valores intrínsecamente literarios.

El jesuita Miguel A. Bernad presentó en esta misma colección un breve artículo (pp. 518-526) que es, quizás, a pesar de su brevedad, lo más comprehensivo que se ha publicado sobre las condiciones en que se escribía durante el período colonial. Bernad apunta como hechos culturales relevantes, llevados a cabo por la Iglesia, la llegada de la imprenta, la creación de escuelas y el sentido de unión bajo una misma religión: "the Spanish conquest made us one people" (p. 519). La prolífica publicación de gramáticas, diccionarios, doctrinas y crónicas de los frailes se cita como ejemplo de la ingente actividad cultural, no estrictamente religiosa, realizada por los misioneros. La presencia ubicua de los frailes en un archipiélago escasamente colonizado por población civil confirió peculiar unidad a un conjunto de islas étnicamente heterogéneo y condicionó de manera muy estricta todo aquello que se publicó en el archipiélago hasta la segunda mitad del siglo xIx. En este sentido, las órdenes religiosas trajeron consigo la cultura de la letra impresa y, con ella, un inmenso caudal de conocimientos no sólo en teología o filosofía, sino también en medicina, música, arquitectura o ciencias exactas: una revolución cultural de grandes proporciones cuya expansión e influencia no se han estudiado con la meticulosidad que el tema merece ${ }^{37}$.

Otro jesuita, el estadounidense John N. Schumacher, es el autor -en la misma compilación de Manuud- del que hasta hoy puede considerarse el artículo más sustancioso en cuanto a los escritos de tema nacionalista durante la segunda mitad del siglo xIx. Gran conocedor

${ }^{36}$ De hecho, esto es lo que, consecuentemente, procede a realizar en el artículo: una lectura minuciosa de una estrofa de Fernando de Bagongbanta y de "Mi retiro", de José Rizal. Véase, en el mismo volumen, el artículo de Miguel Bernad 1967a, pp. 527-538, uno de los pocos trabajos que analizan las novelas rizalianas desde un punto de vista estrictamente literario.

${ }^{37}$ No se ignora aquí que muchas de estas disciplinas ya existían en el archipiélago, sino que por primera vez se atendió a ellas como un cuerpo de estudios organizados y transmitidos en el entorno de instituciones creadas al efecto. Cf. JoHN Leddy Phelan 1965, que, a pesar de haber sido superado en muchos puntos, sigue siendo una buena introducción al tema, como demuestra, por otra parte, su reciente reedición en 2011. 
de los acontecimientos de este turbulento período ${ }^{38}$, Schumacher traza una inadvertida e interesante línea de continuidad desde los folletos de protesta del padre Peláez hasta los escritos de los colaboradores de La Solidaridad, cuyo común denominador no sería únicamente el ansia de reformas (Rizal) o la consecución de la independencia (Marcelo del Pilar), sino una rica discusión en torno a los problemas inmediatos del país (Sancianco) y una búsqueda, a veces desesperada, de la identidad propia, que establece un diálogo de gran interés con los escritos del período colonial (Paterno, Pardo de Tavera, Isabelo de los Reyes) y de la raíces indígenas del pueblo filipino. Esta mirada hacia los primeros cronistas provocará, curiosamente, la publicación de un gran número de ensayos de carácter histórico-antropológico -algunos de ellos ciertamente estrafalarios-, la edición anotada por Rizal de los Sucesos de las Islas Filipinas (1609), de Antonio de Morga, y el nacimiento de la primera novela de autor filipino: Ninay. Costumbres filipinas (1885), de Pedro Paterno ${ }^{39}$. El artículo de Schumacher, de gran densidad informativa, abre vías hacia la investigación literaria de un período en el que la figura del héroe nacional ha dejado en la penumbra a gran número de pensadores y literatos. Se trata de un momento cultural tremendamente productivo sin el cual la obra del mismo Rizal no puede entenderse ${ }^{40}$.

La década de los años setenta asistió a la virtual desaparición del sistema de literatura filipina en español. La mengua en el número de hablantes significó irremisiblemente la disminución de lectores y de autores, así como la escasez de editoriales dispuestas a publicar y la reducción de la prensa escrita en español, que empezaba ya a verse desde hacía algunos años como el vestigio de un tiempo pasado. Dos artículos de Edward C. Knowlton Jr. (1962 y 1985), publicados con veintitrés años de diferencia, atestiguan este declive imparable ${ }^{41}$. En el primero de ellos, da cuenta de la vitalidad de la lengua española en Manila, resalta el interés de un grupo reducido pero entusiasta de profesores y traductores, informa acerca de las connotaciones peyorativas -en cuanto elitista y esnob- que tiene el español entre los fili-

38 Cf. especialmente los trabajos de John N. Schumacher 1981, 1991 y 1997, clásicos ya de la historiografía de la época.

${ }^{39}$ Schumacher no trata la poesía, género que, en cambio, se estudia en Miguel BERNAD 1974.

${ }^{40}$ Este deseo de recuperación se encuentra detrás de la publicación de Resil Mojares 2006, la cual demuestra convincentemente que Rizal no surgió por generación espontánea, sino dentro de una atmósfera intelectual favorable. Sin embargo, su encumbramiento como héroe nacional sigue emborronando la dimensión intelectual de su proteica figura. Analizaremos esta importante contribución en un próximo estudio que estamos preparando acerca del progreso de los estudios literarios hispanofilipinos desde el año 2000 hasta hoy.

${ }^{41}$ Cf. además B. Cailles Unson 1969, que debe leerse más como un artículo de reivindicación que como un estudio crítico. 
pinos y confirma la existencia de tan sólo dos periódicos: El Debate y Nueva Era. También reseña la existencia de representaciones dramáticas en español y enumera una corta lista de publicaciones literarias en español entre 1959 y 1961. El profesor norteamericano, que se declara defensor de la lengua de Cervantes, termina su artículo previendo la eventual desaparición de la literatura hispanofilipina. Ya en la década de los años ochenta, el mismo Knowlton Jr. no pudo sino confirmar las predicciones que había realizado dos décadas antes: cada vez eran menos los escritores en lengua española y más difícil publicar, dado que iban quedando pocos lectores. El itinerario de ganadores del Premio Zóbel era indicativo de esta tendencia: desde los años setenta, el premio se otorgaba a obras no literarias o de calidad más que dudosa, pues también había disminuido el número de candidatos. En esta ocasión, el profesor apuntó la existencia de tres escritores: Federico Espino Licsi, Guillermo Gómez Rivera y Edmundo Farolán, los dos últimos, curiosamente, todavía activos.

La historia de la literatura hispanofilipina recibe su segundo intento sintetizador con la breve monografía de Luis Mariñas (1974), que pasa por ser, hasta hoy, y pese a su brevedad y deficiencias, lo más accesible y citado de cuanto se ha publicado en esta área de estudio. Comprimidos en apenas ochenta páginas, los autores y sus obras se enumeran con comentarios que rara vez superan las cinco líneas. La introducción trata el discutido tema del grado de penetración de la lengua española en Filipinas, comenta a grandes rasgos el ingrediente hispánico en el seno de la heterogénea identidad filipina y confirma el declive de la lengua a lo largo del siglo xx. Los capítulos siguen una periodización como aquella propuesta por Alinea, aunque con algunos matices: bajo el marbete "los primeros balbuceos de la literatura fil-hispana", se mezclan indiscriminadamente los corridos, la zarzuela, las doctrinas cristianas, las primeras gramáticas, la Historia general de las Islas Philipinas de fray Juan de la Concepción ${ }^{42}$, e incluso el Maragtas ${ }^{43}$ y el denominado "Código de Kalantiaw" ${ }^{44}$. La etapa

42 Publicada en catorce volúmenes entre 1788 y 1892 a la muerte de su autor, y centrada en hechos de la vida civil, se trata de una obra tan exhaustiva y curiosa cuanto poco explorada por los historiadores.

43 Pequeña narración ilonga en verso sobre la llegada de los primeros datus de Borneo a la isla de Panay. La tradujo el padre agustino Tomás Santarén a fines del siglo xix y apareció publicada como apéndice en Ángel Pérez 1902, pp. 383-397.

44 Desde su aparición en 1912, se pensó que el citado código era prueba de la existencia de un sistema de justicia prehispánico. William Henry Scott demostró en 1984 que el documento aludido no era más que un timo fabricado por un tal José Negros, quien pretendía sacar algún beneficio. Cf. W.H. Scotr 1984, pp. 104-135. A pesar de su demostrada falsedad, este código se sigue incluyendo en los libros de historia escolares y el Kalantiaw Museum sigue funcionando, lo cual es bastante indicativo de lo difícil que es erradicar discursos espurios cuando arraigan en un patriotismo mal entendido. 
formativa estaría constituida por todo lo escrito entre 1800 y 1873 , dado que, en opinión de Mariñas, durante este lapso es cuando el escritor toma "conciencia de su peculiar personalidad nacional y trata de darle expresión literaria” (p. 27). Esta intuición no aparece acompañada de un número significativo de pruebas o ejemplos, pues repite, sin citar, lo que otros autores habían afirmado anteriormente ${ }^{45}$. La literatura nacionalista se enclava entre 1873 y 1903, absorbiendo así el breve período revolucionario apuntado por Alinea. La Edad de Oro se termina hacia 1930, año en que se presentan más candidatos al Premio Zóbel, buen índice para conocer la vitalidad de la literatura hispanofilipina ${ }^{46}$. Finalmente, los dos últimos capítulos son especialmente útiles para conocer a la última generación de autores en español, de los cuales se nos ofrece una provechosa lista.

La obra de Mariñas es, en cierto modo, un ensayo que aborta y elude todo desarrollo argumentativo. Aunque atiende a criterios literarios, la información que ofrece es siempre insuficiente y la periodización, una rehechura, bastante mejorada, de aquella de Alinea. Toda la literatura anterior a 1873 se despacha en apenas seis páginas, mientras que los capítulos más sustanciosos son de poca utilidad por cuanto nos ofrece una numerosísima lista de autores, obras y publicaciones periódicas, muchas veces sin comentario alguno. Estos valiosos datos necesitarían una apoyatura en forma de referencias que se nos niega, ya que no están acompañados de notas a pie de página ni citas bibliográficas. Para dificultar la tarea del investigador, no se informa siquiera si la obra fue publicada o si permaneció inédita, fenómeno bastante frecuente en la literatura hispanofilipina del siglo $\mathrm{xx}$, o dónde quedan ejemplares de la obra en cuestión, dato especialmente relevante sobre todo si tenemos en cuenta su poca difusión y la dificultad para encontrar títulos ${ }^{47}$.

La llamada de Manuud a una lectura en términos estrictamente literarios de la novela filipina en español finalmente tuvo respuesta en un artículo del historiador y crítico cultural Florentino Hornedo, leído en 1978 y finalmente publicado en 1980 bajo el título "Notes

45 Durante este período vio la luz una ingente cantidad de publicaciones periódicas en cuyas páginas apareció la mayor parte de la actividad literaria. Estos periódicos y revistas, apenas reseñados por Wenceslao Retana en el tomo tercero de su Aparato General (1906) y en El periodismo en Filipinas (1908), necesitan ser examinados para poder comprender el modo en que la literatura moderna surgió en el archipiélago y reconstruir el sistema literario que dominó durante la mayor parte del siglo Xıx. La tarea es ardua por la escasez de material y su dispersión, pero necesaria.

46 Mariñas (1974, p. 71) señala que ya en 1934 se decidió no otorgar el premio a ningún autor dada la poca calidad de las obras recibidas.

47 Verbigracia, no hemos encontrado ejemplar alguno de la revista dedicada al Modernismo, Domus Aurea (1908), ni sabemos si queda algún ejemplar de la novela El último romántico (1922), de Antonio Abad, ganadora del primer Premio Zóbel. 
on the Filipino novel in Spanish"48. Hornedo afirma que las raíces de la novela hispanofilipina se encuentran en la literatura española del siglo xIX y señala tres aspectos, en su opinión, fundamentales: el género costumbrista, del que se hizo eco Paterno en Ninay (1885); las novelas de Pérez Galdós y su crítica social, presente en las novelas de Rizal, y las ideas liberales del krausismo. Selecciona ocho obras en prosa de ficción, que constituyen en sí mismas una propuesta de itinerario o de canon de literatura hispanofilipina, según su representatividad y su calidad intrínseca: la mencionada Ninay, Noli me tangere (1887) y El filibusterismo (1891), de José Rizal; los cuentos de Aurora social (1910-1911), de Paterno; las novelas Bancarrota de almas (1910), Se deshojó la flor (1915) y Los pájaros de fuego (1945), de Jesús Balmori (1887-1948), y las novelas de quien quizás fuera el mejor novelista en lengua española de Filipinas durante el siglo xx, el cebuano Antonio M. Abad (1894-1970): La oveja de Nathán (1928) y La vida secreta de Manuel Espeña (1960). El profesor Hornedo se muestra especialmente elogioso con La oveja de Nathán:

La Oveja de Nathan is not only a condemnation of American imperialism during the first quarter of the twentieth century: it is also a dissertation by a social philosopher upon a great variety of topics from the "Great War" to the homelife of the rich and the poor in Manila and Cebú (p. 143) ${ }^{49}$.

Hornedo sostiene que la lengua española nunca fue la lengua del pueblo filipino (en consecuencia, apenas fue capaz de transmitir los sentimientos y las problemáticas de la gente común) y que la literatura murió a la par que la élite que la escribió y leyó (pp. 156-158). Considero, sin embargo, que estas apreciaciones son algo injustas: que la lengua fuera escrita por una minoría no significa necesariamente que perteneciera a la élite. Autores como Enrique Laygo o Antonio Abad formaban parte de una modesta clase media cuyos problemas exponían. La poesía modernista filipina, parangonable a la hispanoamericana, posee un indudable sabor local y está salpicada de apelaciones constantes al sentir del pueblo filipino. Por último, ese mismo criterio pudiera aplicarse a las novelas de Nick Joaquin (19172004) o de Francisco Sionil José (n. 1924), pues están escritas en una lengua, el inglés, que apenas entiende un porcentaje mínimo de la población. De cualquier modo, el artículo de Hornedo es un trabajo de mucha entereza que acomete con interpretaciones originales y

${ }^{48}$ Esta primera publicación vio la luz en Saint Louis University Research Journal, septiembre de 1980, pp. 383-422, publicación de University of Baguio. Cito, sin embargo, por su reedición de 2001.

${ }^{49}$ El tema del conflicto identitario entre lo hispano y lo anglosajón en los autores hispanofilipinos, interpretado como una nostalgia del perdido edén hispano, se trata de manera muy somera en NoRA Jolipa 1996, pp. 24-32. 
juicios de valor una serie de novelas que merecía, por fin, una lectura más detenida y desprejuiciada.

No ocurre así con los artículos de Nora Jolipa y Vivencio Jose, profesores ambos de la Universidad de Filipinas, quienes -siguiendo la línea de Teófilo del Castillo- enjuician las obras literarias según su compromiso con las aspiraciones de la nación filipina. El primer artículo de Jolipa (1978) es, en su totalidad, un recorrido presuroso por una veintena de autores: registra, como antes hicieran Epifanio de los Santos y del Castillo, a Bangongbanta y Pinpin como únicos autores filipinos antes del siglo XIX; no considera las novelas de Felipe del Pan, Chápuli Navarro y Entrala de Paula por no ser capaces de ver Filipinas como víctima de la injusticia española (p. 166); valora positivamente los primeros poemas de Rizal y la novela Ninay de Pedro Paterno, tradicionalmente denostada por la crítica, por cuanto constituyen pruebas de su adhesión patriótica; considera el cuento "Fray Botod" de G. López Jaena, el primer trabajo literario en el que se ataca el colonialismo español (p. 172) y establece un nexo directo entre las tesis defendidas en El filibusterismo (1891), de José Rizal, y el primer intento de revolución en 1896. El ímpetu revolucionario es igualmente la principal virtud de los poemas de Emilio Jacinto (1875-1899), Cecilio Apóstol y Fernando María Guerrero, mientras que interpreta la hispanofilia de obras como La carrera de Cándida (1921), de G. Gómez Wyndham, el poema épico De Mactán a Tirad (1941), de Flavio Zaragoza Cano (1892-1994), y los Cuentos de Juana (1943), de Adelina Gurrea (1896-1971), como estrategia reaccionaria y de protesta al colonialismo estadounidense.

En su segundo artículo (1981), Jolipa aplica el mismo criterio reduccionista al estudio de la crítica literaria escrita en español al distinguir tres períodos en la crítica: una larga fase, que termina en 1872, en la que predominan los moralistas cristianos ${ }^{50}$. Jolipa reprueba especialmente los postulados críticos del dominico Valentín Marín Morales (1860-1921), profesor de literatura en la Universidad de Santo Tomás, quien publicó las primeras obras de teoría literaria en el archipiélago $^{51}$, ya que condenaba, según su moralismo, las teorías clásicas que entraban en conflicto con los intereses cristianos (p. 336) ${ }^{52}$. A continuación, celebra la llegada hacia 1880 de una tradición crítica que, en su opinión, "finds its origins in the Filipino's needs and

50 Sin embargo, ninguno de los autores que cita dentro de esta tradición crítica realiza su obra antes de 1872 .

51 Una aproximación a su trayectoria intelectual puede encontrarse en JorGE Mojarro Romero 2015.

52 Paradójicamente, Jolipa acusa a estos autores por querer subordinar el placer estético a los deberes religiosos y morales, cuando ella misma celebra precisamente la subordinación del placer estético al compromiso patriótico exigido por el momento histórico. 
aspirations" (p. 337). En este sentido, distingue entre nacionalistas (1873-1903) -López Jaena y Rizal-y nacionalistas de segunda generación (1904-1942) -Epifanio de los Santos, T.M. Kalaw, Jaime de Veyra, F.M. Guerrero, Manuel Briones y Claro M. Recto-, autores todos que harán uso de la crítica literaria como arma política.

Este sentimiento anticolonial se exacerba en el trabajo de Vivencio Jose (1984), que tiene como asunto el estudio de la producción poética entre 1895 y 1910, aproximadamente, y en que el estudioso comienza denigrando en todas sus facetas el colonialismo español y termina culpando a los estadounidenses de la falta de perfección de la poesía filipina en español. Jose ignora la fidelidad del poeta F.M. Guerrero al Modernismo y a sus postulados estéticos, afirmados repetidamente en varios ensayos y en los prólogos que escribió a poetas amigos; y apartando deliberadamente la numerosa poesía de evasión, de sentimiento o de religiosidad, se centra en la poesía de tema revolucionario o que tiene simplemente a Filipinas como asunto principal. Jose entiende que la primera influencia de los poetas proviene del Romanticismo, dadas sus ansias de libertad, y que "la poesía es un instrumento efectivo de lucha histórica" (p. 230). Esta manifiesta preferencia por la poesía de compromiso ha impedido una justa apreciación de la calidad lírica de obras como Rimas malayas (1904), de Jesús Balmori, o Crisálidas (1914), de F.M. Guerrero, entre otras, donde la poesía de reivindicación política es muy secundaria.

Esta miopía nacionalista vuelve a aparecer en uno de los contados trabajos que indagan con profundidad y erudición por entre los poco transitados caminos de la novela anterior a 1898. Escrita con el propósito de trazar una línea de continuidad en la novela filipina desde los cantos épicos de los indígenas hasta las modernas narraciones de 1940, la pionera monografía del profesor cebuano Resil Mojares (1998 [1983]) no sólo falla en demostrar la tesis que propone, puesto que las novelas de Paterno y Rizal surgen esencialmente como correlatos filipinos de tendencias literarias en boga en Europa y Latinoamérica durante el siglo XIX -las novelas costumbristas y fundacionales ${ }^{53}$-, sino que vuelve a utilizar la literatura como instrumento de refuerzo de una joven conciencia nacional y desecha una valiosa oportunidad para describir el proceso literario de la novela en su totalidad. Mojares dedica dos largos capítulos a la novela filipina anterior a 1898: "The Early Colonial narratives", que abarca desde la llegada de la imprenta hasta la primera mitad del siglo xIX, y "The Late Colonial narratives", que se ocupa de la segunda mitad del siglo xix.

El énfasis en la aportación a la novela escrita en lenguas vernáculas se intensifica en los capítulos dedicados a la narrativa entre 1900 y 1940: no incluye a ningún autor filipino en lengua española a pesar

${ }^{53}$ Cf. J. Mojarro Romero 2017. 
de ser el período de apogeo de la literatura filhispana, mientras que dedica tan sólo quince páginas al surgimiento de la literatura filipina en inglés. Su rastreo cronológico lo lleva a afirmar la práctica inexistencia de literatura filipina antes de 1800, dado que casi nada había sido escrito por nativos antes de esa fecha (p. 46); y así, desconsidera la primera novela escrita en tagalog, una traducción del Barlaam y Josafat publicada en 1712, por haberla llevado a cabo el jesuita español Antonio de Borja (p. 59). Asimismo, guarda juicios despectivos para los romances métricos (corridos y awits), imaginativas narraciones en verso en tagalo y productos originales del sincretismo literario (p. 70); luego, califica de "medieval" toda la literatura anterior al siglo XIX arguyendo un supuesto aislacionismo en el archipiélago hasta 1860 (p. 97). Tampoco considera filipinas las novelas de un grupo de escritores peninsulares a pesar de que desarrollaron toda su carrera literaria en el archipiélago y tomaron Filipinas como el tema principal de sus narraciones (p. 125) ${ }^{54}$; siguiendo a Castillo, entiende, en definitiva, que la intrusión de la nueva cultura literaria llevó consigo la desaparición de una rica literatura autóctona, a la vez que la censura atrofió el desarrollo de una verdadera literatura moderna (p. 99).

Todas esas afirmaciones son en realidad coherentes si se sigue el estricto criterio de lengua, nacimiento y raza ${ }^{55}$ que Mojares preconiza y aplica a todas las obras que analiza, pero ese criterio se vuelve un obstáculo a la hora de validar las mismas novelas de José Rizal, publicadas en español y fuera de Filipinas: Mojares se ve impelido a afirmar entonces que Noli me tangere y El filibusterismo son filipinas por motivación, tema e intención (p. 152). Al no considerar la literatura filipina como un sistema heterogéneo en el que confluyen diferentes tradiciones y estilos, de lo culto a lo popular, de lo escrito a lo transmitido oralmente, de lo pagano a lo religioso, y al borrar del marco toda la literatura colonial con su diversidad de géneros y sus relaciones con la literatura europea, Mojares acaba por mostrar un cuadro trunco de literatura filipina en el que las obras autóctonas aparecen aisladas, sin razón de continuidad, hasta 1898 y en el que las primeras narraciones modernas parecen brotar por generación espontánea.

LOS AÑOS NOVENTA: UNA DÉCADA DE AVANCES

El libro de Mojares encuentra su contrapunto en Edgardo Tiamson Mendoza, profesor de español de la Universidad de Filipinas, quien

54 Estos autores se estudian en L. Hernandez Chung 1998. Véase el análisis de esta obra más adelante.

55 Mojares afirma que Peláez y Burgos son españoles nacidos en Filipinas (p. 126). 
publicó en junio de 1993 escasas copias mecanografiadas del que quizás sea, pese a sus carencias, el mejor trabajo panorámico acerca de la literatura filhispana desde sus orígenes hasta la actualidad: A re-appreciation of Philippine literature in Spanish (1993). El propósito de la obra queda claro en la "Introducción", no así la metodología usada, que deberá deducirse del mismo texto. Comienza su trabajo denunciando la ligereza con que algunos profesores filipinos han asumido afirmaciones falsas, como la referente a la destrucción del patrimonio literario indígena filipino por parte de los misioneros, pues constituyen una evidente distorsión de los hechos históricos, de la que afirma contundentemente: "the glorification of our pre-Hispanic past at the expense of the historical truth is cheap scholarship" (p. 3), con lo que llama de nuevo la atención, como ya hiciera Manuud, sobre la problemática relación entre una manipuladora historiografía nacionalista y un conjunto de textos que reclama una lectura, como poco, desinteresada. La obra se propone simplemente presentar, sin prejuicios, la historia del patrimonio literario filipino escrito en lengua española, mientras admite las deficiencias de su trabajo pionero, excesivamente panorámico, debidas principalmente a la dificultad para acceder al material. Metodológicamente simple, procede a una lisa separación por siglos, sin denominaciones de períodos y sin apenas referencias históricas, que aparecen reducidas al mínimo ${ }^{56}$.

Lo más destacado e innovador de las siete páginas que Tiamson Mendoza dedica al siglo XVI es su carácter incluyente, quizás algo excesivo, como reacción al rechazo crítico anterior. Para la literatura elaborada durante los siglos siguientes, el profesor manileño incluye

${ }^{56}$ Así, en lo que se refiere al período colonial, cita el informe de Maximiliano Transilvano -De Moluccis Insulis-, que titula erróneamente Relación sobre el viage de Magallanes (1523). Para un recuento de las expediciones de Magallanes y Loaysa, cita la Historia general de las Indias, de Gonzalo Fernández de Oviedo, aunque no especifica que se trata en concreto de su libro XX (1557). Luego pasa a comentar elogiosamente el trabajo de los industriosos primeros misioneros: Espejo claro de rico corazón (1590), una colección de proverbios filosóficos chinos traducidos por el sinólogo dominico Juan Cobo (1547-1591) que, sin embargo, no vio la luz en forma impresa hasta 1924. Asimismo, informa que en 1593 se estampó uno de los tres primeros libros impresos en Filipinas: la Doctrina christiana en lengua española y tagala. También anota el importante informe de Miguel de Loarca: Tractado de las Yslas Philippinas (1582), incluye Costumbres de los yndios tagalos de Filipinas (1589) del franciscano Juan de Plasencia (¿?-1590), pero yerra al incorporar las Antiguas leyendas (1578) de López Povedano, cuya falsedad se había demostrado años antes (Sсотт 1984). Curiosamente, incluye una carta del gobernador Francisco de Sande (1540-1602), aunque ninguna de las varias relaciones de Legazpi. Por último, anota la Historia de las cosas más notables, ritos y costumbres del gran reyno de la China (1585), publicada por primera vez en Roma por el agustino Juan González de Mendoza (1540-1617), quien jamás estuvo en Asia y sólo colateralmente menciona Filipinas, y la Historia de las islas del archipiélago y reynos de la gran China, Tartaria, Cuchinchina, Malacca... (1601) del cronista franciscano Marcelo de Ribadeneyra. 
no sólo obras de algún valor literario, sino también gramáticas y diccionarios. En este sentido, su trabajo esboza un itinerario muy acucioso de la historia de la imprenta filipina: el profesor Mendoza enumera sermones, crónicas, relatos de sucesos, libros de fiestas, compendios, manuales para misioneros y, en general, cualquier obra publicada en tierras filipinas. A partir del siglo XIX antologa, con profusión, poemas y prosas, acompañándolos de comentarios breves y sagaces, pero en ningún caso cita la edición de la que proceden los textos. El extenso capítulo dedicado al siglo xx es una fuente inagotable de datos, sobre todo en lo que se refiere a nombres de autores y revistas literarias, aunque faltan de nuevo indicaciones precisas que orienten al futuro investigador: fuentes, fechas, localizaciones, pistas que permitan indicar, por lo menos, dónde se encuentra todo ese material. En definitiva, desde el punto de vista de la historia literaria, el trabajo de Tiamson Mendoza es sin lugar a dudas el más exhaustivo y panorámico de cuantos se han publicado hasta la fecha. Es lástima, sin embargo, que tal mina de datos, acumulados a veces sin comentario alguno, sufran de la falta de método y de una elaboración poco cuidadosa.

Otro considerable avance en los estudios literarios hispanofilipinos lo constituye el artículo de Peralta-Imson (1997), pues trata cuestiones relevantes desde una perspectiva novedosa. Ante todo, se pregunta acerca de qué debe formar parte de la literatura hispanofilipina y opta por un procedimiento inclusivo. Así, al igual que Manuud o Mendoza, estima que forma parte de la literatura hispanofilipina toda obra escrita en español independientemente de la etnicidad $u$ origen del autor, siempre que la obra sea literaria, artística o creativa, y haya sido tradicionalmente considerada representativa del desarrollo de la literatura en Filipinas. Es, además, la primera estudiosa que trata de definir algunas características esenciales de esta literatura: por ejemplo, su íntima relación con el periodismo ${ }^{57}$, la escasez de obras estrictamente literarias durante el período español, la insuficiencia permanente de público lector, la existencia a un mismo tiempo de religiosidad y anticlericalismo o la manifestación de un intenso amor por la lengua y la cultura españolas. Son estas cuestiones que la autora no desarrolla, pero que cabe explorar cuando se posea un conocimiento más detallado del corpus literario y surjan nuevos trabajos orientados al estudio de obras y autores concretos ${ }^{58}$.

El surgimiento de la novela moderna en el sistema literario filipino de la segunda mitad del siglo xix constituye el tema de estudio de la monografía de L.H. Chung: Facts in fiction: A study of peninsular prose

57 Véase supra nota 45.

58 La autora pasa a continuación a esbozar una periodización que, salvo algunos cambios terminológicos, sigue fundamentalmente la trazada por Alinea. 
fiction, 1859-1897 (1998 $)^{59}$. Su propósito no es estudiar a los autores filipinos de ese período, sino a los autores peninsulares instalados en Manila que, publicando novelas folletinescas o seriadas en los periódicos, contribuyeron enormemente al desarrollo del género. Chung distingue tres subgéneros dentro de la novela popular decimonónica filipina: la novela de aventuras, la prosa costumbrista y la novela de corte moral. Su recorrido por las diferentes obras, algunas de difícil localización, es exhaustiva. Destacan autores como el prolífico José Felipe del Pan (1821-1891), Antonio García del Canto (1824-1886), Francisco Cañamaque (1851-1891), Antonio Vázquez de Aldana (¿?1891) y Francisco de Paula Entrala, hombres todos cruciales en la historia del periodismo en Filipinas. Sus novelas son más interesantes desde el punto de vista sociológico que literario, aunque algunas de ellas merecen, en opinión de la estudiosa, una lectura atenta: Sin título (Manila, 1881), de Vázquez de Aldana; El cofre cerrado (Manila, 1883), de Entrala; Un naufragio de la brickbarca Genoveva en la Isla de la Cruz Blanca (Manila, 1889), de J.F. del Pan, y Pepin (Madrid, 1891), de A. Chápuli Navarro. La obra de Chung, necesariamente panorámica, es pionera y abre interesantes vías de investigación inexploradas: la eclosión del moderno periodismo y su protagonismo en el quehacer literario, el papel de las traducciones de autores europeos, el tratamiento de la dualidad filipino/ español, la visión desidealizada del exotismo o la simple relectura pormenorizada de algunas de las obras mencionadas son tarea pendiente que podría dilucidar muchos aspectos del tardío surgimiento de la novela en la ultraperiferia del imperio español.

En 1998, la profesora Lacónico-Buenaventura dio por fin a la imprenta un completísimo estudio acerca de los primeros cien años del teatro moderno en Manila ${ }^{60}$, del que había dado un prometedor avance en 1979. La monografía no trata únicamente del teatro en español, sino también del escrito en inglés y en tagalo. Asimismo, lleva a cabo un trabajo exhaustivo de documentación para completar una historia del teatro con especial énfasis en sus aspectos sociológicos: la historia efímera de los primeros locales, las asociaciones y grupos locales, la regulación de las funciones a finales del siglo XIX, la aparición de las primeras figuras distinguidas y las discusiones en torno a la creación de un verdadero teatro nacional son temas que aparecen tratados con rigor. Además, la monografía se acompaña de numerosas fotografías de época de personajes, teatros y documentos de difícil localización, así como de un nutrido apéndice con

59 La publicación del libro fue sorprendentemente tardía, si tenemos en cuenta que un breve adelanto apareció en 1970 bajo el título "An introduction to peninsular prose of fiction, 1859-1897”, Asian Studies, 8, 3, pp. 386-393.

${ }^{60}$ Manejo la segunda edición publicada en 2010. 
documentación traducida al inglés en que se puede acceder a un listado de las obras que se representaban y el precio que se pagaba por verlas. De particular interés para el hispanista es el capítulo en que se estudia el declive del teatro en tagalo y en español a causa, en opinión de la autora, de la falta de profesionalidad de los actores y la inviabilidad financiera del negocio teatral (pp. 105-112). Los estudios de Mendoza, Peralta-Imson, Chung y Lacónico-Buenaventura son la constatación de que, pese a la barrera lingüística y a la variedad de perspectivas, a partir de la última década del siglo xx resurge el interés entre los investigadores locales por el estudio del legado hispánico en Filipinas.

Debemos reseñar, por último, la obra de Ortiz Armengol, estudioso de la obra galdosiana, quien durante varios años ejerció como embajador español en Filipinas. Fruto de esa estancia en el archipiélago es su no suficientemente conocida Letras en Filipinas (1999), colección de pequeños y variados ensayos de tema literario. Modestamente escritos al alimón de su curiosidad, estos articulillos atestiguan la íntima relación, mantenida por medio de la escritura, entre Filipinas y España. Armengol censura en el prólogo, como ya hiciera Manuud, la ceguera nacionalista que ha impedido la justa crítica y valoración de todo lo escrito en español en el archipiélago ${ }^{61}$; su libro se propone, como enmienda decidida, derrumbar imprecisiones y ofrecer, en cambio, pruebas artísticas de ese vínculo histórico. Y aunque la literatura hispanofilipina no constituya propiamente el eje de estas breves incursiones, las referencias a ella son tan recurrentes que la obra de Armengol bien merece ser incluida en este repaso al estado de la cuestión. El crítico madrileño considera, sin melancolías y con buen criterio, que "la literatura en español en Filipinas es un fenómeno ya concluido" (p. 13), y extiende esa denominada "Edad de Oro" de la literatura filhispana a los primeros cuarenta años del siglo xx. Es ésta la primera obra en que se dedican sustanciosas páginas a la literatura prehispánica recogida por los misioneros, al relato de Pigafetta, a la labor lascasiana de los frailes agustinos y dominicos y a esa curiosa tríada de obras de literatura hispanosínica surgida hacia 1590 en Binondo, el barrio de los sangleyes. Con una prosa divulgativa que no renuncia al dato erudito, comenta las menciones de Filipinas en Lope, Góngora y Quevedo; divaga acerca de las tempranas historias de Argensola y Antonio de Morga; reflexiona brevemente acerca del olvidado siglo XVIII filipino; presenta al lector el género teatral de las

${ }^{61}$ "El aludido nacionalismo parece haberse inclinado a ignorar algunas realidades históricas bien evidentes y, apartándose, elige desconocer buena parte de ellas e imagina sueños y paraísos perdidos en los que todo bienestar y toda felicidad era lo único existente en una nación adelantada y en una sociedad dichosa, la cual fue perturbada por la intrusión de otros pueblos, que hicieron retroceder todo lo que ya existía” (p. 11). 
pasiones e indaga en las motivaciones y vaivenes del jesuita Alemany, misionero en Zamboanga y autor de una Tercera Parte de El Buscón (1768), cuya trama, parcialmente, tiene lugar en el archipiélago ${ }^{62}$. Su visión amplia del fenómeno literario explica su interés por los textos publicados antes de la segunda mitad del siglo xix; en este sentido, se puede considerar a Ortiz Armengol como pionero en el acercamiento a la literatura hispanofilipina colonial. Se trata, pues, de un trabajo valioso, a pesar de su heterogeneidad, su falta explícita de pretensiones y su poca sistematización -apenas un orden cronológico-, que quizás habría tenido mayor repercusión de haberse publicado en una editorial especializada en humanidades ${ }^{63}$.

\section{Conclusiones}

El estudio de la literatura hispanofilipina a lo largo del siglo xx jamás gozó de sustento institucional en Filipinas o fuera del archipiélago, donde sólo llegaron a conocerse las obras de José Rizal, ni se concretó en un área de estudios autónoma ${ }^{64}$. Desde Retana hasta Ortiz Armengol, las incursiones críticas en la literatura hispanofilipina se llevaron a cabo de manera más bien asistemática, con una periodización absolutamente plegada a la historia externa de Filipinas en la que se echa en falta un intento por establecer un corpus organizado de autores según criterios puramente estéticos o literarios. A excepción de la obra de Castillo, que contó durante varias décadas con el respaldo del sistema educativo y contribuyó a su apartamiento del patrimonio literario filipino, los estudios literarios hispanofilipinos se debieron a escasas iniciativas individuales y aisladas, realizadas por personas cultas y bienintencionadas cuyos esfuerzos, sin embargo, no se materializaron en obras orgánicas de referencia ni lograron llamar la atención de historiadores y críticos literarios en España y Latinoamérica. Nuestra crítica a la politización de Retana y la apropiación de historiadores nacionalistas -lógica, por otra parte, tratándose de una nación joven- se explica porque consideramos que se

${ }^{62}$ Fue rescatada por el incansable W. Retana con un estudio introductorio en la Revue Hispanique, tomo 54 (1922). En 1998, Celsa C. García Valdés editó la obra para EUNSA, Pamplona.

${ }^{63}$ Añado, por último, y como curiosidad, La caución más fuerte (2000), escrita por otro embajador, Delfín Colomé, la cual podría considerarse como una bienintencionada síntesis redactada por un aficionado a las letras. No aporta nada en puridad desde el punto de vista de la investigación; se ocupa, en cambio, de antologar textos escritos por filipinos en que España y la lengua española son el tema recurrente. El título está tomado de un soneto del poeta manileño Fernando María Guerrero (1873-1929).

${ }^{64}$ Hay un buen número de tesis de maestría y doctorales llevadas a cabo por estudiantes filipinos en la Universidad de Filipinas, fundamentalmente. WySTAN DE LA Peña 2000 se refiere a algunas de ellas. 
trata, principalmente, de una utilización espuria, aunque muy legitimada en estos últimos años por ciertas corrientes críticas, como la teoría postcolonial, para servir a una determinada agenda. Pero, sobre todo, porque ha contribuido enormemente a enturbiar la comprensión de la literatura filipina en lengua española y valorarla en su esencialidad: textos literarios con cualidades estéticas.

El estudio de la literatura filipina en lengua española sólo ha empezado a recibir cierta y continuada atención por parte de un pequeño número de investigadores desde hace relativamente pocos años. La actual falta de vinculación identitaria del pueblo filipino con la lengua española; la progresiva desaparición de autores, obras y lectores; el derrumbe del sistema literario hispanofilipino en la década de los años sesenta; la drástica reducción de los hablantes de español; la inexistencia de estudios literarios y filológicos en las universidades filipinas, dignos de tal nombre hasta los años ochenta, y la situación periférica de la literatura hispanofilipina con respecto al resto de literaturas en lengua española son algunas de las razones que pueden esgrimirse para explicar este prolongado abandono crítico. Será sólo en el siglo XXI cuando un grupo de jóvenes investigadores, mayormente de España y EE.UU., vuelva su mirada al patrimonio literario hispanofilipino para rescatarlo del olvido con los instrumentos de la filología moderna y cuando algunas instituciones y editoriales, casi siempre foráneas, se decidan a realizar un trabajo de recuperación que llevaba demorándose demasiado tiempo ${ }^{65}$.

\section{REFERENCIAS}

Abella, Domingo 1967. "Some notes on the historical background of Philippine literature", en Brown heritage. Essays on Philippine cultural tradition and literature. Ed. A. Manuud, Ateneo de Manila University Press, Quezon City, pp. 34-48.

Aduarte, Diego de 1962 [1640]. Historia de la Provincia del Santo Rosario de la Orden de Predicadores en Filipinas, Japón y China. Ed. Manuel Ferrero, CSIC, Madrid.

Alemany, Vicente 1998 [1768]. Andanzas del Buscón don Pablos por México y Filipinas. Ed. Celsa C. García Valdés, Universidad de Navarra, Pamplona.

Alinea, Estanislao 1964. Historia analítica de la literatura filipinohispana, Imprenta Los Filipinos, Ciudad de Quezón.

Alinea, Estanislao 1967. "Philippine literature in Spanish. From the literature of protest to efflorescence", en Brown heritage. Essays on Philippine cultural tradition and literature. Ed. A. Manuud, Ateneo de Manila University Press, Quezon City, pp. 508-517.

Arcilla, Jose S. 1972. "Philippine education: Some observations from history", Philippine Studies, 20, 2, pp. 273-286.

Barrantes, Vicente 1889. El teatro tagalo, Tipografía de Manuel G. Hernández, Madrid.

${ }^{65}$ Como he avanzado en nota 40, esperamos dar a la luz muy pronto un artículo que recoja los últimos avances en el estudio de la literatura hispanofilipina. 
Bazaco, Evergisto 1953. History of the education in the Philippines, Universidad de Santo Tomás, Manila.

Bernad, Miguel A. 1967. "Some aspects of Rizal's novels", en Brown heritage. Essays on Philippine cultural tradition and literature. Ed. A. Manuud, Ateneo de Manila University Press, Quezon City, pp. 527-538.

Bernad, Miguel A. 1967a. "The church and Philippine literature in the Spanish Era”, en Brown heritage. Essays on Philippine cultural tradition and literature. Ed. A. Manuud, Ateneo de Manila University Press, Quezon City, pp. 518-526.

Bernad, Miguel A. 1974. "Poets of the Philippine Revolution", Philippine Studies, 22, 1/2, pp. 81-92.

Blancas de San José, Francisco 1606. Memorial de la vida cristiana, Juan de Vera, Binondo.

Blanco Andrés, Roberto 2011. "Pedro Peláez: líder del clero filipino”, Hispania Sacra, 63, 128, pp. 747-782.

Brillantes, Lourdes 2000. 80 Años del Premio Zóbel, Instituto Cervantes-Fundación Santiago, Manila.

Cailles Unson, Ben 1969. "La literatura hispanofilipina”, Archivum, 19, pp. 275-291.

Cabrero Fernández, Leoncio 1973-74. "Orígenes y desarrollo del teatro en Filipinas", Anales de Literatura Hispanoamericana, 2/3, pp. 83-96.

CANo, Glòria 2008. "La cara oculta de Retana: una nueva aproximación histórica a su obra”, Illes $i$ Imperis, 10/11, pp. 273-302.

CANO, GLòria 2008a. "Wenceslao Retana revisited: A new historical assessment", en More Hispanic than we admit. Insights in Philippine cultural history. Ed. Isaac Donoso, Vibal Foundation, Quezon City, pp. 263-301.

Castillo y Tuazon, Teófilo del 1937. A brief history of Philippine literature, Progressive Schoolbooks, Manila.

Chung, Lilia Hernandez 1970. "An introduction to peninsular prose of fiction, 1859-1897”, Asian Studies, 8, 3, pp. 386-393.

Chung, Lilia Hernandez 1998. Facts in fiction: A study of peninsular prose fiction, 1859 1897, De La Salle University Press, Manila.

Cobo, JuAn 2005. Espejo rico del claro corazón. Ed. Li-Mei Liu, Letrúmero, Madrid.

Colomé, Delfín 2000. La caución más fuerte, Los Libros del Instituto Cervantes, Manila.

De la Peña, Wystan 2000. "Fil-hispanic literary studies: Current trends and challenges in the 21st Century", Philippine Humanities Review, 4, pp. 8-34.

De Llobet, Ruth 2009. "El poeta, el regidor y la amante. Manila y la emergencia de una identidad criolla filipina”, Istor. Revista de Historia Internacional, 38, pp. 65-92.

De Llobet, Ruth 2015. Luis Rodríguez Varela, el Conde Filipino: A filipino pamphletist, 1791-1824, tesis, University of Singapore.

De los Santos, Cristóbal Epifanio 1914. "Nuestra literatura a través de los siglos", en M.M. Norton, Builders of a nation, E.C. McCullough, Manila, pp. 53-72.

De Veyra, Jaime C. 1958. "La hispanidad en Filipinas", en Historia general de las literaturas hispánicas. Dir. G. Díaz-Plaja, Barna, Barcelona, 1958, t. 5, pp. 509-525.

Decena, Marcelo G. 1965. Literatura filipino-hispana durante la revolución y la revolución filipina, s.e., Manila (mecanografiado).

Donoso, IsAac 2010. "The Hispanic moros y cristianos and the Philippine komedya”, Philippine Humanities Review, 11, pp. 87-120.

Donoso, IsAAC 2014: "El Renacimiento europeo en la formación de la literatura clásica de Filipinas", eHumanista. Journal of Iberian Studies, 19, pp. 407-425.

Fox, Henry Frederick 1954. "Current expense appropriations for public elementary education, 1881-1896”, Philippine Studies, 2, 4, pp. 341-359.

Fox, Henry Frederick 1965. "Primary education in the Philippines, 1565-1863", Philippine Studies, 13, 2, pp. 207-231. 
Hornedo, Florentino 2001. "Notes on the Filipino novel in Spanish", Ideas and ideals. Essays in Filipino cognitive history, University of Santo Tomas Press, Manila, pp. 109-158.

JOLIPA, NORA 1978. "The impact of Spanish colonialism on Philippine literature in Spanish", Philippine Social Sciences and Humanities Review, 42, 1/4, pp. 164-194.

Jolipa, Nora 1981. "Philippine literary criticism in Spanish: A tradition of commitment", Philippine Social Sciences and Humanities Review, 45, 1/4, pp. 333-344.

Jolipa, Nora 1996. "Lost Paradise: American colonialism and the Filipino writer in Spanish", en Nationalist literature. A centennial forum. Ed. Elmer A. Ordoñez, University of the Philippine Press-PANULAT, Quezon City, pp. 24-32.

Jose, Vivencio R. 1984. "Reform and revolution: Developing a Philippine poetry in Spanish", Philippine Humanities Review, 1, 1/2, pp. 217-238.

Knowlton, JR., EDWARd C. 1962 "Hispano-Philippine literature: A recent view", Books Abroad, 36, 4, pp. 380-382.

Knowlton, Jr., Edward C. 1985. "Hispano-Philippine literature in the Marcos Era", World Literature Today, 59, 1, pp. 37-40.

Lacónico-Buenaventura, Cristina 1979. "The theaters of Manila: 1846-1896", Philippine Studies, 27, 1, pp. 5-37.

Lacónico-Buenaventura, Cristina 2010 [1998]. The theater in Manila, 1846-1946, $2^{\text {a }}$ ed., De La Salle University Press, Manila.

Manuud, Antonio G. 1967. "Toward a theory concerning the development of Filipino poetry in Spanish", en Brown heritage. Essays on Philippine cultural tradition and literature. Ed. A. Manuud, Ateneo de Manila University Press, Quezon City, pp. 457-482.

Mariñas, LuIs 1974. Literatura filipina en castellano, Editora Nacional, Madrid.

Martínez, Miguel 2016. "La cuarta salida. Un testimonio inédito sobre el Quijote en las Filipinas (1623)", en Cervantes ayer y hoy. Eds. Nuria Morgado y Lía Schwartz, Hispanic Society of America, New York, pp. 109-134.

Martínez, Miguel 2017. "Don Quijote, Manila, 1623: orden colonial y cultura popular”, Revista Hispánica Moderna, 70, 2, pp. 143-159.

Mendoza, Edgardo Tiamson 1993. A re-appreciation of Philippine literature in Spanish, s.e., 2 ts. (copia mimeografiada).

Mojares, Resil 1998. Origins and rise of the Filipino novel. A generic study of the novel until 1940, University of the Philippines Press, Quezon City.

Mojares, Resil 2006. Brains of the nation, Ateneo de Manila University Press, Quezon City.

Mojarro Romero, Jorge 2015. "An essay on Ensayo de una síntesis de los trabajos realizados por las corporaciones religiosas de filipinas by Fr. Valentín Marín, O.P.”, en Lumina Pandit. A continuum. Ed. Ángel Aparicio, UST Miguel de Benavides Library-UnionBank of the Philippines, Manila, pp. 159-194.

Mojarro Romero, Jorge 2017. "Rizal y las novelas fundacionales de Hispanoamérica", Transpacific Exchanges, 1, pp. 95-102.

Mojarro Romero, Jorge 2018. "Los primeros libros impresos en Filipinas (15931606)", Hispania Sacra (en prensa).

Ortiz Armengol, Pedro 1999. Letras en Filipinas, Ministerio de Asuntos Exteriores, Madrid.

Panganiban, Jose Vila y Consullo T. Panganiban s.f. [196?]. The literature of the Filipinos, Alip and Sons, Sampaloc.

Peralta-Imson, M. Elinora 1997. "Philippine literature: Spanish evolving a national literature", Linguae et Litterae, 2, pp. 1-19.

PÉREZ, ÁNGEL 1902. Igorrotes. Estudio geográfico y etnográfico sobre algunos distritos del norte de Luzón, El Mercantil, Manila.

Phelan, John Leddy 1965. The hispanization of the Philippines, The University of Wisconsin Press, Madison. 
PinPin, ToMÁs 2012. Librong Pagaaralan nang manga Tagalog nang uicang Castilla. Ed. D. Woods, UST Press, Manila.

Preyssler, Margarita Z. 1955. Temática de la poesía filipina en su siglo de oro (18701930), Real y Pontificia Universidad de Santo Tomás, Manila.

Recto, Claro M. 1911. Bajo los cocoteros, Librería Manila Filatélica, Manila.

Retana, Wenceslao E. 1894. El precursor de la política redentorista. Breves comentarios a un libro raro, Imprenta de la Viuda de M. Vinuesa de los Ríos, Madrid.

Retana, Wenceslao E. 1908. La censura de imprenta en Filipinas, Victoriano Suárez, Madrid.

Retana, Wenceslao E. 1909. Noticias histórico-bibliográficas del teatro en Filipinas desde sus orígenes hasta 1898, Victoriano Suárez, Madrid.

Retana, Wenceslao E. 1909a. De la evolución de la literatura castellana en Filipinas. Los poetas, Victoriano Suárez, Madrid.

Retana, Wenceslao E. 1924. "Noticias de dos escritores filipinos: Manuel de Zumalde, Luis Rodríguez Varela", Revue Hispanique, 62, 142, pp. 377-439.

Sagrada fiesta tres vezes grande: que en el decurso de tres días zelebró el Convento de Santo Domingo en Manila, primera casa de la Provincia del Sancto Rosario de Filippinas: en la beatificación de los gloriossos sanctos Pío Quinto, Diego de Bebaña y Margarita de Castello 1677. Colegio y Universidad de Santo Tomás, Manila.

SAn Agustín, Delfina de 1935. La literatura castellana en Filipinas, tesis, Universidad de Santo Tomás, Manila.

Schumacher, John N. 1967. "The literature of protest: Peláez to the Propagandists", en Brown Heritage. Essays on Philippine cultural tradition and literature. Ed. A. Manuud, Ateneo de Manila University Press, Quezon City, pp. 483-507.

Schumacher, John N. 1981. Revolutionary clergy: The Filipino clergy and the nationalist movement, 1850-1903, Ateneo de Manila University Press, Quezon City.

Schumacher, John N. 1997. The propaganda movement, 1880-1895, Ateneo de Manila University Press, Quezon City.

Schumacher, John N. 2008. "Wenceslao E. Retana in Philippine history", en The making of a nation, Ateneo de Manila University Press, Quezon City, pp. 134-155.

Scott, William Henry 1984. Prehispanic source materials for the study of Philippine history, New Day Publishers, Quezon City.

Soriano, Rosa Reyes 1965. Cultura hispano-filipina. Breve historia de la literatura hispano filipina, Nueva Era Press, Manila.

Urzáiz, Héctor 2002. Catálogo de autores teatrales del siglo XVII, FUE, Madrid, t. 2.

Wendt, Reinhard 1998. "Philippine fiesta and colonial culture", Philippine Studies, 46,1, pp. 3-23.

Wolf 2ND, EDwin 1947 [1593]. "Doctrina christiana". The first book printed in the Philippines, Library of Congress, Washington.

Zugasti, Miguel 2016. "Dos ejemplos de teatro breve cómico hispanofilipino: el Entremés del envidioso y el Sarao agitanado entre ocho hombres y mujeres (Manila, 1677)", América sin Nombre, 21, pp. 141-165. 